\title{
The hanta hunting study: underdiagnosis of Puumala hantavirus infections in symptomatic non-travelling leptospirosis-suspected patients in the Netherlands, in 2010 and April to November 2011
}

M Goeijenbier (m.goeijenbier@erasmusmc.nl)1, R A Hartskeerl², J Reimerink³ , J Verner-Carlsson4, J F Wagenaar ${ }^{2}$, M G Goris $^{2}$, B E Martina $^{1}$, Å Lundkvist ${ }^{4,5}$, M Koopmans ${ }^{1,3}$, A D Osterhaus ${ }^{1}$, E C van Gorp ${ }^{1,6}$, C B Reusken ${ }^{1,3,6}$

1. Erasmus MC, Department of Virology, Rotterdam, the Netherlands

2. Royal Tropical Institute (KIT), KIT Biomedical Research, Amsterdam, the Netherlands

3. Centre for Infectious Disease Control, National Institute for Public Health and the Environment (RIVM), Bilthoven, the Netherlands

4. The Public Health Agency of Sweden, Solna, Sweden

5. Department of Medical Biochemistry and Microbiology, Uppsala University, Uppsala, Sweden

6. These authors share senior authorship

Citation style for this article:

Goeijenbier M, Hartskeerl RA, Reimerink J, Verner-Carlsson J, Wagenaar JF, Goris MG, Martina BE, Lundkvist Å, Koopmans M, Osterhaus AD, van Gorp EC, Reusken CB. The hanta hunting study: underdiagnosis of Puumala hantavirus infections in symptomatic non-travelling leptospirosis-suspected patients in the Netherlands, in 2010 and April to November 2011 . Euro Surveill. 2014;19(32):pii=20878. Available online: http://www.eurosurveillance.org/ViewArticle.aspx?Articleld=20878

Leptospirosis and haemorrhagic fever with renal syndrome (HFRS) are hard to distinguish clinically since these two important rodent-borne zoonoses share hallmark symptoms such as renal failure and haemorrhage. Leptospirosis is caused by infection with a spirochete while HFRS is the result of an infection with certain hantaviruses. Both diseases are relatively rare in the Netherlands. Increased incidence of HFRS has been observed since 2007 in countries that border the Netherlands. Since a similar rise in incidence has not been registered in the Netherlands, we hypothesise that due to overlapping clinical manifestations, hantavirus infections may be confused with leptospirosis, leading to underdiagnosis. Therefore, we tested a cohort of non-travelling Dutch patients with symptoms compatible with leptospirosis, but with a negative diagnosis, during 2010 and from April to November 2011. Sera were screened with pan-hantavirus IgG and IgM enzyme-linked immunosorbent assays (ELISAs). Sera with IgM reactivity were tested by immunofluorescence assay (IFA). ELISA (IgM positive) and IFA results were confirmed using focus reduction neutralisation tests (FRNTs). We found hantavirus-specific IgG and/or IgM antibodies in $4.3 \%(11 / 255)$ of samples taken in 2010 and in $4.1 \%(6 / 146)$ of the samples during the 2011 period. After FRNT confirmation, seven patients were classed as having acute Puumala virus infections. A review of hantavirus diagnostic requests revealed that at least three of the seven confirmed acute cases as well as seven probable acute cases of hantavirus infection were missed in the Netherlands during the study period.

\section{Introduction}

Hantaviruses, negative-stranded RNA viruses belonging to the Bunyaviridae family, can cause severe disease in humans. Depending on the type of hantavirus, either haemorrhagic fever with renal syndrome (HFRS) or hantavirus cardiopulmonary syndrome may occur after inhalation of virus-containing aerosols [1]. HFRS is characterised by acute renal failure, fever (above $38.5^{\circ} \mathrm{C}$ ) and potentially accompanied by severe bleeding complications [2]; it is a notifiable disease in the Netherlands. HFRS cases are found in large parts of Europe and Asia [3]. Pathogenic hantaviruses are rodent-borne and each of these viruses are spread by a specific rodent species. For the HFRS-causing hantaviruses, these include Apodemus, Myodes, Rattus and possibly Microtus species [4,5]. The causative agent of HFRS known to be endemic in the Netherlands is Puumala virus (PUUV), which is spread by its chronically infected reservoir, the bank vole (Myodes glareolus) [6]. Symptomatic cases of PUUV infection may develop mild HFRS, often referred to as nephropathia epidemica. Recent reports describe PUUV infections with a broader clinical spectrum, ranging from mild febrile cases, without renal impairment or haemorrhage, to severe respiratory manifestations without any signs of renal involvement $[7,8]$. Historically, the occurrence of PUUV infection in the Netherlands has been restricted to the eastern and southern parts of the country, with an incidence of 25-30 cases reported per year (approximately 0.04-0.18 cases per 100,000 population) [9]. Since 2007, several studies have described an increase in the number of human PUUV infections in neighbouring countries at the eastern (Germany) and southern borders (Belgium) [10-12]. To date, a similar 
increase in the number of human PUUV infections has not been observed in the Netherlands.

In the early 1990s, Groen et al. tested 8,892 sera obtained in the Netherlands from different risk groups, such as renal disease patients, and subjects from suspected occupational risk groups, such as forestry workers and military personnel, for the presence of hantavirus antibodies [13]. The highest prevalence (up to $6 \%$ ) was seen in participants with known occupational risk factors associated with increased rodent exposure [13,14]. Data (which are as yet unpublished but a summary of the main results is available) from a large serum bank study in the Netherlands that started in 2006 showed a hantavirus seroprevalence, in a cross-sectional population based study, of $1.7 \%$ [15]. Given that $70-80 \%$ of PUUV infections are asymptomatic and that only $5-10 \%$ of symptomatic patients will probably seek medical attention [16], the 25-30 cases reported every year in the Netherlands (with a population of 16.8 million [17]) are indicative of potential underdiagnosis of hantavirus infections $[4,5]$. In 2011, we described a case report of a patient with nephropathia epidemica diagnosed outside the area known to be endemic for hantavirus circulation in the Netherlands, Overijssel [18]. Although the patient had visited a known PUUV-endemic area, this information in the patient history did not result in rapid diagnosis of the cause of the disease, illustrating unawareness of hantavirus infections.

Leptospira, a genus of helical-shaped bacteria, forms another important group of causative agents of rodentborne haemorrhagic fever in the Netherlands [19]. Pathogenic Leptospira cause leptospirosis, which shares many clinical manifestations with HFRS, such as renal failure, thrombocytopenia and potential bleeding complications [3]. Interestingly, two studies, from Italy and Sri Lanka, showed an increased hantavirus seroprevalence in patients suspected of having leptospirosis. Compared with control groups consisting of office personnel or healthy blood donors, the number of confirmed cases of hantavirus infection was significantly higher among those who were clinically suspected, by a clinician, of having leptospirosis $[20,21]$. Groen et al. reported a hantavirus seroprevalence of about $1 \%$ in patients suspected of having acute leptospirosis in the Netherlands in samples collected between 1972 and 1994 [13]. The actual prevalence of confirmed acute leptospirosis was slightly higher (3\%) [13].

In the Netherlands, a relatively low number of leptospirosis cases are registered annually, as are HFRS cases, with a reported incidence of 0.25 leptospirosis cases/100,000 population [19]. To investigate the putative underdiagnosis of hantavirus infection in symptomatic patients, we tested a cohort of leptospirosis-suspected, but confirmed-negative, patients with no travel history for the previous three months, for the presence of hantavirus-specific antibodies, using a two-step strategy: pan-hantavirus enzyme-linked
FIGURE 1

Design, inclusion criteria and confirmatory steps of the hanta hunting study, the Netherlands, 2010 and AprilNovember 2011

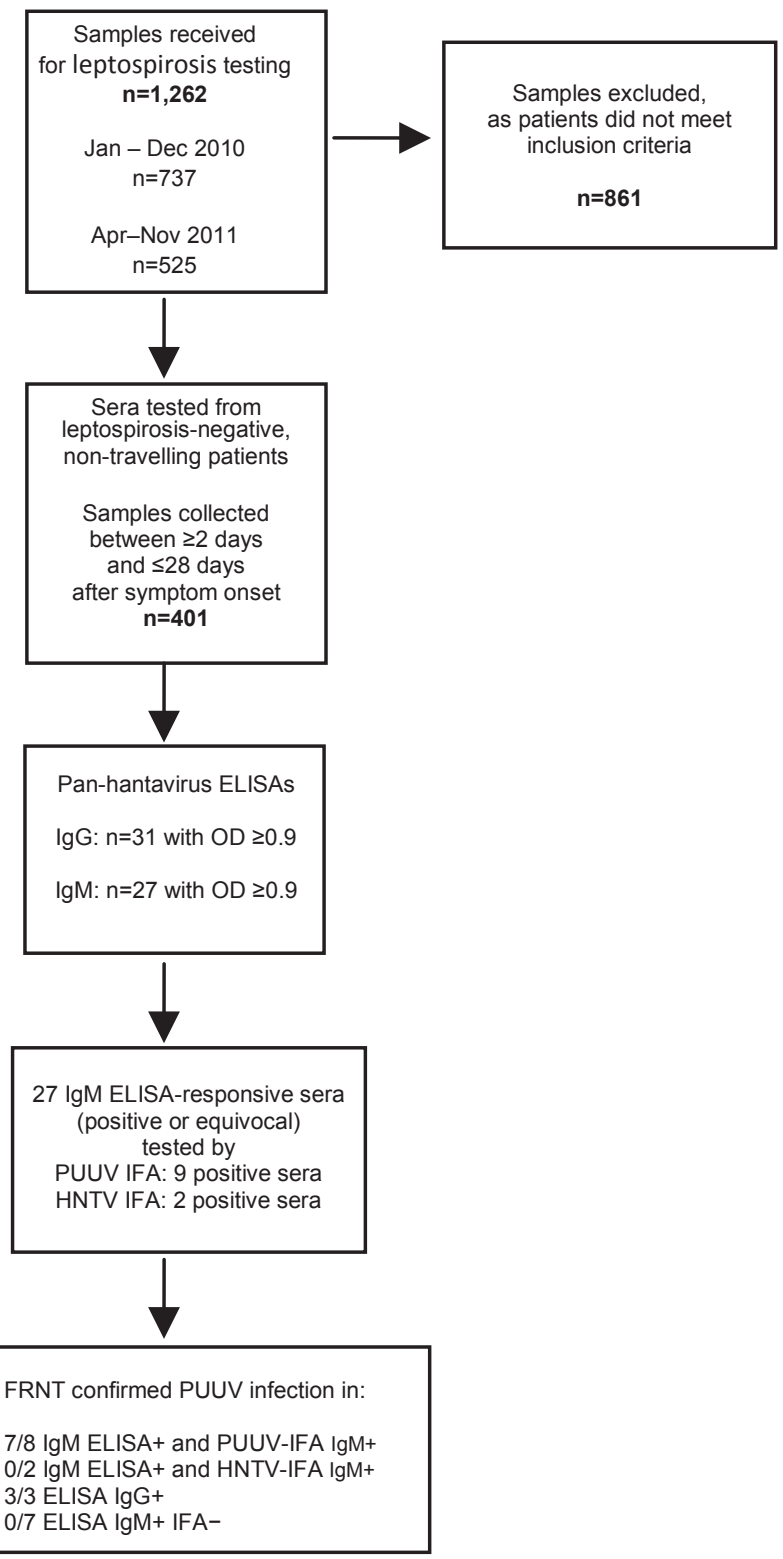

+ Positive test result

- Negative test result

OD: optical density (an OD of $>1.10$ was regarded as positive, between $\geq 0.90$ and $\leq 1.10$ as equivocal and $<0.90$ as negative); ELISA: enzyme-linked immunosorbent assay; FRNT: focus reduction neutralisation test; HNTV: Hantaan virus; IFA: immunofluorescence assay; PUUV: Puumala virus.

The rationale for the chosen period was an overall increase in hantavirus activity in countries neighbouring the Netherlands (Germany and Belgium) (January-December 2010) [4] and the known season of PUUV activity in northern and western Europe (April-November 2011) [26]. 
immunosorbent assays (ELISAs) followed by two separate immunofluorescence assays (IFA): one to detect PUUV serogroup antibodies and one to detect Hantaan virus (HNTV) serogroup antibodies (HNTV was used as it belongs to the same serogroup as Seoul hantavirus (SEOV). Recent evidence indicates the circulation of SEOV in Europe [22-24], spread by Rattus norvegicus, which is also a well-known carrier of Leptospira [3]). To confirm the ELISA and IFA results, focus reduction neutralisation tests (FRNTs) were used, the gold standard technique in hantavirus serology. All IFA IgM-positive sera were tested in the FRNT with PUUV virus. In addition, because recent evidence indicates the circulation of SEOV in Europe, we included SEOV, as well as Dobrava virus (DOBV), in the FRNT, although not the main aim of this study, to gain insight into the potential introduction of these viruses in the Netherlands.

\section{Methods}

\section{Serum bank}

Sera from non-travelling Dutch patients with a negative leptospirosis diagnosis - based on a microscopic agglutination test (MAT), ELISA and culture performed at the National Leptospirosis Reference laboratory (NRL) at the Royal Tropical Institute (KIT) in Amsterdam - were included in our study. A sample was deemed to be negative for leptospirosis if the patient did not meet the case definition for leptospirosis - i.e. the inhouse ELISA for leptospirosis was below the cut-off titre of 1:80 and the MAT showed no relevant titre of Leptospira-specfic antibodies (11:160) [25]. The study cohort was taken from submissions of sera to the NRL in 2010, as a large increase in the number of PUUV infections in Germany and Belgium were observed that year [4]. In addition, we also included sera from patients meeting the above inclusion criteria that were received by the NRL during April to November 2011, the season for PUUV activity in northern and western Europe [26] (Figure 1).

As we were interested in patients who had pan-hantavirus IgM antibodies, we selected patients whose samples had been collected at least two days after symptom onset, up to four weeks (28 days) after symptom onset. All samples were heat inactivated (30 minutes at $56{ }^{\circ} \mathrm{C}$ ) and stored at $-20{ }^{\circ} \mathrm{C}$ until testing. Requests for leptospirosis testing were accompanied by a standardised form with information about place of residence, travel history, presenting symptoms and occupation: these data were reviewed.

Hantavirus underdiagnosis was assessed by checking if testing for hantavirus was requested at either of the hantavirus diagnostic laboratories in the Netherlands (Erasmus MC in Rotterdam and RIVM in Bilthoven) for any of the pan-hantavirus ELISA-responsive sera (equivocal or positive result in an IgG or IgM ELISA).

Patients whose sera were responsive in any of the diagnostic tests were ranked by likelihood of hantavirus infection. Patients whose sera were positive in the IgM ELISA, IFA and FRNT were considered a confirmed case of acute hantavirus infection. If only the IgM ELISA was positive (or equivocal) and IFA was positive, the patient was considered a probable acute case. If only the IgG ELISA was positive and therefore IFA was not performed, but the FRNT was positive for PUUV, the patient was also considered a probable acute case. If only the IgM ELISA was positive or equivocal, the patient was considered not a case of hantavirus infection.

\section{Enzyme-linked immunosorbent assay}

Sera were screened using pan-hantavirus IgG and IgM DxSelect ELISAs (Focus Diagnostics). These ELISAs are used for testing a broad range of hantaviruses, although there are variations in sensitivity and specificity per specific hantavirus. According to the material supplied by the manufacturer, the IgM test has an overall sensitivity of $95.1 \%(83.5-99.4 \%)$ and a specificity of $94.1 \%(83.8-98.8 \%)$. The IgG test has comparable performance characteristics, with an overall specificity of $95 \%(91.4-100 \%)$ and a sensitivity of $95 \%(75-$ $98 \%$ ); both tests are compared with a reference ELISA by external investigators. For the Netherlands, the performance of these ELISAs in detecting antibodies to PUUV and, potentially, SEOV, is of importance. Data supplied by the manufacturer showed a sensitivity of $70 \%(45.7-88.1 \%)$ in the IgM ELISA and 95\% (83.2$100 \%$ in the IgG ELISA for PUUV-specific antibodies, as tested by FRNT. For SEOV FRNT-positive samples, the sensitivity was $50 \%(11.8-88.2 \%)$ in the IgM ELISA and $95 \%(54.1-100 \%)$ in the IgG ELISA.

An optical density (OD) of $>1.10$ was regarded as positive, between $\geq 0.90$ and $\leq 1.10$ as equivocal and $<0.90$ as negative.

\section{Immunofluorescence assay}

ELISA IgM-positive or equivocal sera were tested in IFA by using commercial slides with PUUV- and HNTVinfected cells (PROGEN Biotechnik). Only IgM-reactive samples were chosen as these are indicative of a recent infection, possibly related to the clinical symptoms that were the basis of the initial request for leptospirosis testing. IFA was used because of its higher reported specificity and the possibility of being able to distinguish between PUUV- or HTNV-like serotype infections (manufacturer's insert, PROGEN Biotechnik). Before testing, the sera were incubated with liver acetone powder from calves (Sigma-Aldrich, Germany) to reduce background fluorescence. For the IgM test, the sera were pretreated with GullSORB (Meridian Bioscience Inc., United States) to reduce isotype competition. Sera were serially diluted twofold starting at 1:32 and incubated on the slides for 1 hour at $37^{\circ} \mathrm{C}$. After this step, the wells were incubated with either a fluorescein isothiocyanate (FITC)-labelled goat antihuman IgG or IgM conjugate. Fluorescence was scored under an immunofluorescence microscope. The cut-off titre for a positive result was defined as the sample dilution for which specific fluorescence was greater 
Serological test results from samples selected for focus reduction neutralisation test confirmation of hantavirus infection, the Netherlands, 2010 and April-November 2011 ( $n=22)$

\begin{tabular}{|c|c|c|c|c|c|c|c|c|c|c|c|}
\hline \multirow{2}{*}{$\begin{array}{l}\text { Sample } \\
\text { number }\end{array}$} & \multirow{2}{*}{$\begin{array}{c}\text { Date of } \\
\text { sampling }\end{array}$} & \multicolumn{2}{|c|}{ ELISA $^{a}$} & \multicolumn{4}{|c|}{ IFA $^{\mathrm{b}}$} & \multicolumn{3}{|c|}{$\mathrm{FRNT}^{\mathrm{c}}$} & \multirow{2}{*}{$\begin{array}{c}\text { Acute hantavirus } \\
\text { infection } \\
\text { case status }\end{array}$} \\
\hline & & $\lg M$ & $\lg G$ & $\begin{array}{l}\text { PUUV } \\
\text { IgM }\end{array}$ & $\begin{array}{l}\text { PUUV } \\
\text { IgG }\end{array}$ & $\begin{array}{l}\text { HNTV } \\
\text { IgM }\end{array}$ & $\begin{array}{l}\text { HNTV } \\
\text { IgG }\end{array}$ & PUUV & SEOV & DOBV & \\
\hline \multicolumn{12}{|c|}{ PUUV IFA IgM positive } \\
\hline 4 & May 2010 & POS & POS & 1:128 & $1: 128$ & NEG & $1: 128$ & POS & NEG & NEG & Confirmed \\
\hline 7 & Jul 2010 & POS & POS & $1: 128$ & $1: 128$ & $1: 128$ & NEG & POS & NEG & NEG & Confirmed \\
\hline 10 & Aug 2010 & POS & POS & $1: 128$ & $1: 128$ & NEG & $1: 128$ & POS & NEG & NEG & Confirmed \\
\hline 11 & Aug 2010 & POS & POS & 1:128 & $1: 128$ & NEG & NEG & POS & NEG & NEG & Confirmed. \\
\hline 12 & Aug 2010 & POS & Equi & $1: 128$ & $1: 128$ & NEG & NEG & POS & NEG & NEG & Confirmed. \\
\hline 14 & Aug 2010 & POS & NEG & 1:128 & $1: 128$ & NEG & NEG & NEG & NEG & NEG & Probable \\
\hline 19 & Jul 2011 & POS & POS & $1: 128$ & $1: 128$ & $1: 128$ & $1: 128$ & POS & NEG & NEG & Confirmed \\
\hline 21 & Sep 2011 & POS & NEG & 1:128 & $1: 128$ & NEG & NEG & NS & NS & NS & Probable \\
\hline 22 & Sep 2011 & POS & Equi & $1: 128$ & $1: 128$ & $1: 128$ & $1: 128$ & POS & NEG & NEG & Confirmed \\
\hline \multicolumn{12}{|c|}{ HNTV IFA IgM positive and ELISA IgM reactive } \\
\hline 6 & Jun 2010 & POS & POS & NEG & NEG & 1:512 & 1:512 & NEG & NEG & NEG & Probable \\
\hline 5 & Jun 2010 & Equi & NEG & NEG & NEG & $1: 128$ & NEG & NEG & NEG & NEG & Probable \\
\hline \multicolumn{12}{|c|}{ ELISA IgM reactive and PUUV or HNTV IFA negative } \\
\hline 2 & Feb 2010 & POS & NEG & NEG & NEG & NEG & NEG & NEG & NEG & NEG & Not a case \\
\hline 3 & Feb 2010 & POS & NEG & NEG & NEG & NEG & NEG & NEG & NEG & NEG & Not a case \\
\hline 13 & Aug 2010 & POS & NEG & NEG & NEG & NEG & NEG & NEG & NEG & NEG & Not a case \\
\hline 15 & Oct 2010 & POS & NEG & NEG & NEG & NEG & NEG & NEG & NEG & NEG & Not a case \\
\hline 17 & May 2011 & POS & NEG & NEG & NEG & NEG & NEG & NEG & NEG & NEG & Not a case \\
\hline 18 & Jul 2011 & POS & POS & NEG & NEG & NEG & NEG & NEG & NEG & NEG & Not a case \\
\hline 20 & Aug 2011 & POS & NEG & NEG & NEG & NEG & NEG & NEG & NEG & NEG & Not a case \\
\hline 9 & Jul 2010 & Equi & POS & NEG & NEG & NEG & NEG & NS & NS & NS & Not a case \\
\hline \multicolumn{12}{|c|}{ Not tested by IFA (as ELISA IgM negative), but ELISA IgG positive } \\
\hline 1 & Feb 2010 & NEG & POS & NT & NT & NT & NT & POS & NEG & NEG & Probable $^{\mathrm{d}}$ \\
\hline 8 & Jul 2010 & NEG & POS & NT & NT & NT & NT & POS & NEG & NEG & Probable $^{d}$ \\
\hline 16 & Apr 2011 & NEG & POS & NT & NT & NT & NT & POS & NEG & NEG & Probable $^{d}$ \\
\hline
\end{tabular}

DOBV: Dobrava virus; ELISA: enzyme-linked immunosorbent assay; Equi: equivocal; FRNT: focus reduction neutralisation test; HTNV G: Hantaan virus; IFA: immunofluorescence assay; NEG: negative; NS: insufficient amount of serum; NT: not tested in IFA (samples not responsive in the IgM ELISA were not tested by IFA); POS: positive; PUUV: Puumala virus; SEOV: Seoul virus.

a ELISA results were scored as positive if $O D>1.10$,equivocal if between $\geq 0.90$ and $\leq 1.10$ and negative if $<0.90$.

b The IFA was scored positive when the reactive titres were $>1: 64$.

The FRNT was scored positive with a cut-off of $80 \%$ virus neutralisation.

IgM antibodies were not detected in these samples, but as hantavirus infection was confirmed by FRNT, the patients were still scored as probable acute hantavirus cases.

than the sample dilution for which specific fluorescence was just identifiable: in this study, it was $>1: 64$.

\section{Focus reduction neutralisation test}

All samples positive in the pan-hantavirus IgM ELISA and PUUV IgM IFA were selected for FRNT confirmation (samples 4, 7, 10, 11, 12, 14, 19, 21 and 22). We also selected two samples positive or equivocal in the panhantavirus IgM ELISA and positive in the IgM HNTV IFA for FRNT (samples 5 and 6). In addition, eight samples that were positive in the IgM ELISA but negative in the IFAs were also selected for FRNT (samples 2, 3, 9, 13, 15, 17, 18 and 20). As a fourth category, three samples that had not been included in the IFA analysis (as they were ELISA IgM negative), but that tested positive in the IgG ELISA (samples 1,8 and 16), were selected for FRNT confirmation.

FRNTs for DOBV strain Slovenia, SEOV strain 80-39 and PUUV strain Kazaan were carried out as described elsewhere [27]. Diluted sera were mixed with an equal volume of diluted virus containing 30-70 focus-forming units $/ 100 \mu \mathrm{l}$. The serum end-concentration was 1:40. The mixture was incubated at $37^{\circ} \mathrm{C}$ for 1 hour and subsequently inoculated into wells of six-well tissue culture plates containing confluent Vero E6 cell 
monolayers. The wells were overlaid with a mixture of agarose and tissue culture medium and incubated for 7-13 days. The agarose was removed from the wells and the cells were fixed. For PUUV-infected cells, polyclonal macaque serum [28] was used as the primary antibody and the monoclonal antibody $\mathrm{1}_{12}$ for DOBV- and SEOV-infected cells as described elsewhere [29]. This step was followed by adding peroxidaselabelled goat-anti-human IgG for the macaque serum and goat-anti-mouse IgG for the ${ }_{1} \mathrm{C}_{12}$ monoclonal antibody to the cells, to indicate virus-infected cells. Tetramethylbenzidine was used as substrate and foci were counted. An $80 \%$ reduction in the number of foci, compared with the virus control, was used as the criterion for virus neutralisation titres.

Review of hantavirus diagnostic requests carried out during suspicion of leptospirosis at the time of sampling

All samples responsive in the IgM and/or IgG pan-hantavirus ELISA were checked for patient-specific characteristics (sex and date of birth). The combination of sex and date of birth was checked in the databases of the hantavirus diagnostic laboratories in the Netherlands. If the sample combination matched the information from the database and the diagnostic request was made in 2010 or 2011, the patient was scored as having been adequately diagnosed for hantavirus disease during the onset of their symptoms. If the sex and date of birth combination could not be found in the databases, but the patient's sample was reactive in any of our tests, the case was scored as a missed probable or confirmed hantavirus case, as described in the serum bank section above.

\section{Ethical issues}

This study was exempted from ethical review of human subject research by the Medical Ethical Review Committee of the Erasmus MC Medical Centre, University of Rotterdam. All data have been anonymised and are not attributable to individual patients.

\section{Results}

Enzyme-linked immunosorbent assay and immunofluorescence assay serology

Of the 1,262 samples received for leptospirosis diagnostic testing during January- December 2010 and April-November 2011, 861 were excluded, as the patients did not meet the inclusion criteria of our study.

All selected and available sera $(n=401)$ were tested by pan-hantavirus ELISAs. Overall, the IgG ELISA resulted in 18 positive and 13 equivocal samples. The IgM testing resulted in 17 positive and 10 equivocal samples. A total of 11 samples reacted in both the $\lg G$ and $\lg M$ ELISAs, bringing the total number of samples that responded in both ELISAs to 47 , i.e. $11.7 \%$ of the 401 samples $(4.3 \%(11 / 255)$ of samples taken in 2010 and $4.1 \%(6 / 146)$ of the samples taken in 2011$)$.
Subsequently, the 27 samples with a positive or equivocal response in the IgM ELISA were tested using both PUUV and HTNV IFAs. In total, nine of the 27 IgM ELISAresponsive samples tested positive for both PUUV IgM and IgG by IFA.

Interestingly, two serum samples were positive in the HTNV IFA, but negative in the PUUV IFA, despite repeated PUUV testing. One of the HTNV-positive samples tested positive for both HNTV IgG and IgM with titres of 1:512; the other sample was positive only for HNTV IgM, with a titre of 1:128.

\section{Confirmation by focus reduction neutralisation test}

FRNT was performed on eight of the nine sera with a positive IgM response in the PUUV IFA (there was an insufficient amount of serum in the ninth sample). It confirmed that seven of the eight samples tested were from patients with recent PUUV infections (samples 4, 7, 10, 11, 12, 19 and 22) (Table 1).

We also tested the two sera with an HNTV IgM-positive IFA and a positive or equivocal ELISA IgM response (samples 5 and 6): both sera were negative by FRNT.

To test if cases had been missed due to lack of sensitivity of the IFAs, we selected eight samples, of which seven samples had enough serum left for FRNT, with only IgM reactivity in the ELISAs and a negative PUUV or HNTV IFA (samples 2, 3, 13, 15, 17, 18 and 20): all seven samples were negative by FRNT.

We also selected three samples that had not been included in the IFA analysis (as they were ELISA IgM negative), but that tested positive in the IgG ELISA (Cases 1,8 and 16). These samples were tested by FRNT because there was a high degree of suspicion of PUUV infection based on the application form for leptospirosis diagnostic request sent by the clinician (e.g. recorded renal failure and possible rodent exposure). All three patients had a long duration of their complaints (more than three weeks since symptom onset, making it possible that hantavirus disease, without the detection of IgM antibodies, was the cause of their symptoms. All three were positive in the PUUV FRNT.

Thus in total, FRNT for PUUV, SEOV and DOBV was performed on 20 of the 22 selected samples, due to an insufficient amount of serum in two samples. Of the 20 serum samples tested, 10 were confirmed as PUUV positive, seven of which were considered due to a recent infection, based on the presence of $\operatorname{lgM}$ antibodies.

\section{Patient characteristics and registered clinical signs and symptoms in confirmed cases} Because of the retrospective nature of our study, we could confirm if patients had been adequately tested for hantavirus infection during their disease course or if the patient was a missed case of PUUV infection. Of the 27 samples with at least an equivocal response in 
Information on cases of hantavirus infection undiagnosed at time of sampling during suspicion of leptospirosis, the Netherlands, 2010 and April-November 2011

\begin{tabular}{|c|c|c|c|c|c|c|c|c|c|}
\hline \multirow{2}{*}{$\begin{array}{l}\text { Sample } \\
\text { number }\end{array}$} & \multirow{2}{*}{$\begin{array}{l}\text { Date of } \\
\text { request for } \\
\text { leptospirosis } \\
\text { testing }\end{array}$} & \multirow{2}{*}{ Sex } & \multirow{2}{*}{$\begin{array}{l}\text { Age group } \\
\text { in years }\end{array}$} & \multirow{2}{*}{ State } & \multirow{2}{*}{$\begin{array}{l}\text { Information at time } \\
\text { of request for } \\
\text { leptospirosis testing }\end{array}$} & \multicolumn{3}{|c|}{$\begin{array}{c}\text { Retroactive hantavirus diagnostic } \\
\text { test results }\end{array}$} & \multirow{2}{*}{$\begin{array}{c}\text { Acute } \\
\text { hantavirus } \\
\text { infection } \\
\text { case status }\end{array}$} \\
\hline & & & & & & ELISAa & IFAb & FRNTC & \\
\hline 16 & Apr 2011 & M & $20-24$ & Overijssel & $\begin{array}{c}\text { Acute kidney failure and } \\
\text { hepatitis }\end{array}$ & $\lg G+$ & NT & PUUV + & Probable \\
\hline 1 & Feb 2010 & M & $20-24$ & Overijssel & $\begin{array}{c}\text { Prolonged severe } \\
\text { disease }\end{array}$ & $\lg G+$ & NT & PUUV + & Probable \\
\hline 8 & Jul 2010 & M & $10-14$ & Groningen & $\begin{array}{c}\text { Contact with soil water } \\
\text { and potential rodent } \\
\text { exposure }\end{array}$ & $\begin{array}{l}\text { IgM Equi } \\
\operatorname{IgG}+\end{array}$ & $\begin{array}{l}\text { PUUV - } \\
\text { HNTV - }\end{array}$ & PUUV + & Probable \\
\hline 21 & Sep 2011 & $\mathrm{~F}$ & $25-30$ & Overijssel & $\begin{array}{c}\text { Icteric; non-responsive } \\
\text { to antibiotics }\end{array}$ & $\lg M+$ & PUUV IgM + & NS & Probable \\
\hline 14 & Aug 2010 & $\mathrm{~F}$ & $20-24$ & Zuid-Holland & $\begin{array}{c}\text { No additional } \\
\text { information }\end{array}$ & $\lg M+$ & PUUV IgM + & All - & Probable \\
\hline 5 & Jun 2010 & M & $20-24$ & Limburg & $\begin{array}{c}\text { No additional } \\
\text { information }\end{array}$ & $\lg M+$ & HNTV IgM + & All - & Probable \\
\hline 6 & Jun 2010 & M & $25-30$ & Gelderland & $\begin{array}{c}\text { Emergency hospital } \\
\text { admission, } \\
\text { to an intensive-care unit }\end{array}$ & $\begin{array}{l}\lg M+ \\
\lg G+\end{array}$ & $\begin{array}{l}\text { HNTV IgM + } \\
\text { HNTV IgG + }\end{array}$ & All - & Probable \\
\hline 22 & Sep 2011 & M & $45-49$ & Gelderland & $\begin{array}{c}\text { Clinical picture not } \\
\text { understood }\end{array}$ & $\begin{array}{l}\lg M+ \\
\lg G+\end{array}$ & $\begin{array}{l}\text { PUUV IgM + } \\
\text { PUUV IgG + }\end{array}$ & PUUV + & Confirmed \\
\hline 19 & Jul 2011 & M & $50-54$ & Groningen & $\begin{array}{l}\text { Extreme tiredness, fever } \\
\text { and diarrhoea }\end{array}$ & $\begin{array}{l}\lg M+ \\
\lg G+\end{array}$ & $\begin{array}{l}\text { PUUV IgM + } \\
\text { PUUV IgG + }\end{array}$ & PUUV + & Confirmed \\
\hline 7 & Jul 2010 & M & $35-39$ & Noord-Brabant & $\begin{array}{c}\text { Severe disease with high } \\
\text { fever and emergency } \\
\text { hospital admission }\end{array}$ & $\begin{array}{l}\lg M+ \\
\lg G+\end{array}$ & $\begin{array}{l}\text { PUUV IgM + } \\
\text { PUUV IgG + }\end{array}$ & PUUV + & Confirmed \\
\hline
\end{tabular}

+ Positive test result

- Negative test result

DOBV: Dobrava virus; ELISA: Enzyme-linked immunosorbent assay; EQUI: equivocal; F: female; FRNT: focus reduction neutralisation test; HNTV: Hantaan virus; IFA: immunofluorescence assay; M: male; NS: insufficient amount of serum; NT: not tested in IFA (samples not responsive in the IgM ELISA were not tested by IFA); PUUV: Puumala virus; SEOV: Seoul virus.

${ }^{a}$ ELISAs for pan-hantavirus IgM and IgG antibodies were used.

${ }^{b}$ For IFA, both PUUV and HNTV sergroups were used.

' For FRNT, PUUV, SEOV and DOBV were used.

the IgM ELISA in our study, which would necessitate further testing of a follow-up serum sample, four were adequately tested by routine serology for hantavirus infection at diagnostic centres at the time of sampling during suspicion of leptospirosis (samples 4, 10, 11 and 12).

The two samples that were responsive in the ELISAs and HNTV IFA, but not in FRNT (samples 5 and 6), were not tested for hantavirus antibodies by ELISA or IFA at the time the patients were sampled.

All available information from retroactively determined probable or confirmed cases of hantavirus infection that were not tested for hantavirus infection during suspicion of leptospirosis at the time of sampling is shown in Table 2. In general, most of the cases were in the eastern parts of the Netherlands. Newly recognised areas with confirmed cases were in the northern province of Groningen and the western province of Zuid-Holland. The missed confirmed and probable cases of hantavirus infection are shown in Figure 2 according to the location of sampling, ranked by likelihood of hantavirus infection, with the highest level of evidence being that of a sample with a positive response in the IgM ELISA confirmed by IFA (IgM and IgG) tests and a positive FRNT result.

\section{Discussion}

In the samples tested, a positive response of hantavirus IgM antibodies in the ELISA was observed in $4.3 \%$ $(11 / 255)$ of samples taken in 2010 and $4.1 \%(6 / 146)$ of the samples taken in 2011. When including samples with an equivocal ELISA result, the overall percentage with an IgM response was $6.7 \%$ (27/401). Confirmation with IFA IgM resulted in a $2.7 \%(11 / 401)$ seropositivity in the cohort. Of these 11 samples, seven were confirmed by FRNT, corresponding to an overall seropositivity in the cohort of almost $2 \%$. However, this percentage could very well be an underestimation. For instance, 
Distribution of probable and confirmed cases of hantavirus infection in the Netherlands, 2010 and April-November 2011 $(\mathrm{n}=14)$

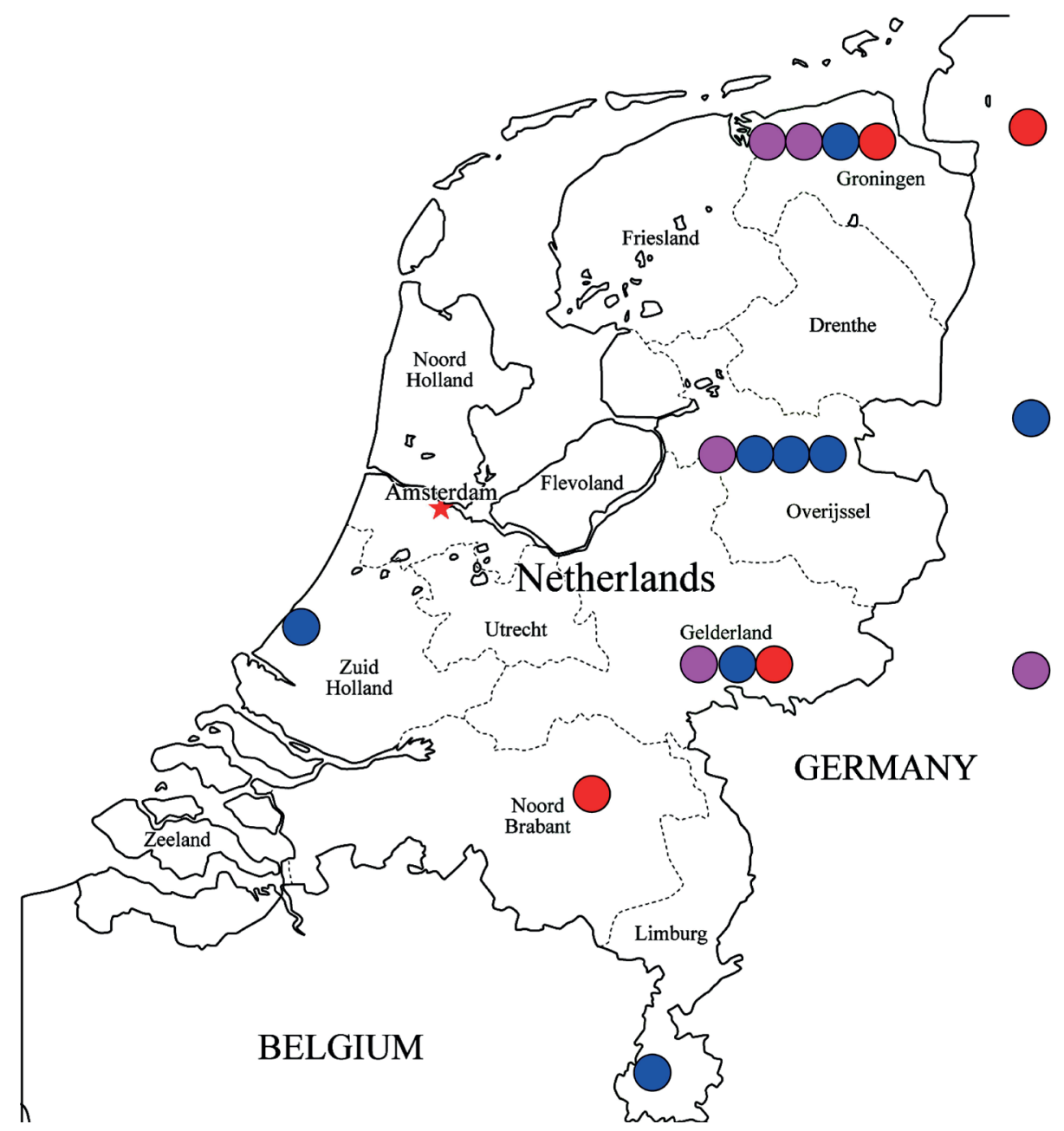

Confirmed case of acute hantavirus infection; not diagnosed

(samples 7, 19, 22)

Probable case of acute hantavirus infection; not diagnosed

(samples 1, 5, 6, 8, 14, 16, 21)

Confirmed case of acute hantavirus infection; diagnosed (samples 4, 10, 11, 12)

The star marks the capital, Amsterdam.

This figure shows the probable and confirmed cases of acute hantavirus infection in the Netherlands and if they were adequately diagnosed during their illness or if these were 'missed' cases. The cases are ranked by likelihood of hantavirus infection. A confirmed case of acute hantavirus infection being that of a positive IgG and IgM response in both pan-hantavirus enzyme-linked immunosorbent assay (ELISA) and immunofluoresence assay (IFA) and a positive result in the focus reduction neutralisation test (FRNT). A probable case is strongly suggestive of an acute case of hantavirus based on ELISA, IFA or FRNT results, but either the FRNT was negative or we were unable to show the presence of IgM antibodies.

one sample could not be confirmed by FRNT due to a lack of available serum after ELISA and IFA screening. It is conceivable that in our cohort of symptomatic patients, of the seven confirmed hantavirus diagnoses, at least three cases were not adequately diagnosed at the time of disease (Cases 7,19 and 22). The other four confirmed cases were found in the databases of the hantavirus diagnostic centres in the Netherlands, and thus were adequately diagnosed at the time of disease. We also identified seven probable cases of acute hantavirus infection: we consider that hantavirus infection was a highly plausible explanation for their symptoms, but either FRNT confirmation was not performed due to the lack of serum or the presence of IgM antibodies (confirming acute infection) could not be proved by ELISA and IFA.
All samples confirmed by FRNT $(n=10)$ only showed PUUV-neutralising activity. The vector of this hantavirus is Myodes glareoulus (bank vole), a small, reddish rodent that inhabits large parts of the Netherlands, solely in grasslands and forests [9]. Case 6, with high $O D$ values in IgM and IgG ELISA screening and a positive HNTV IFA, did not neutralise PUUV, DOBV or SEOV.

This study revealed a high seroprevalence of about $2 \%$ of hantavirus antibodies in a cohort of leptospirosissuspected patients who tested negative for leptospirosis. Leptospirosis in the Netherlands may be either endemic or imported [19]. In our cohort, travel history was well documented and hence we consider it quite certain that the patients we studied contracted hantaviruses in the Netherlands. 
This cohort also gave us the opportunity to study the circulation of hantaviruses other than PUUV in The Netherlands. It is important to monitor this, since evidence is mounting of an increase in the number of SEOV infections in Europe and worldwide, with a recent case reported in the United Kingdom [30]. However, in the samples tested from the Netherlands, the SEOV FRNT was negative. Results were also not indicative for infections with DOBV, which is vectored by the yellownecked mouse (Apodemus flavicollis). It is possible that the ELISA and IFA results in samples 5 and 6 were false positives. The specificity of the ELISA and IFA is below $100 \%$, resulting in a (small) chance of crossreactivity. Test specifications of the ELISA test showed no known cross-reactive pathogens, but this presumption is based on results from very small serum cohorts (manufacturer's insert). Although SEOV and DOBV have been excluded as the causative agents in our study, the remaining hantaviruses in the HNTV serogroup are vectored by reservoir species not known to be present in the Netherlands. Thus, while we cannot rule out the possibility that other hantaviruses from the HNTV serogroup caused the disease in patients from whom samples 5 and 6 were obtained, with no travel history, this remains highly unlikely.

Our results show quite a large discrepancy between the initial ELISA screening, followed by IFA analysis and eventual gold standard FRNT confirmation. Samples that tested positive only in the IgM ELISA $(n=7)$ were not confirmed positive by FRNT. In most cases (7/9), a positive response in the IgM pan-hantavirus ELISA in combination with a positive result in the PUUV IgM IFA was later confirmed by FRNT (sample 14 tested negative in the FRNT and sample 21 could not be tested). Therefore, we underline the importance of FRNT validation in epidemiological studies before drawing any major conclusions, particularly since hantavirus serology is highly prone to giving false-positive results [31].

Acute leptospirosis and HFRS share many clinical manifestations and certain epidemiological features. Exposure to rodents is a known risk factor for both diseases. Hallmark symptoms in both HFRS and leptospirosis include kidney failure. Two of the four cases who were diagnosed at the time of their disease course had documented kidney disorders (data not shown). However, of the 10 cases who were not diagnosed, only one (sample 16) had documented kidney failure. Of the other nine undiagnosed cases, one was described as having 'high fever' (sample 7), two as having 'severe disease' (samples 1 and 7) and one as 'clinical picture not understood' (sample 22): the fact that these cases were undiagnosed in the Netherlands during their disease course could be due to a potential lack of typical presenting symptoms for hantavirus disease in the Netherlands, meaning the absence of kidney failure. Hepatic involvement, often present in leptospirosis one of the classic triads in Weil's disease [3] - could lead a clinician to think of leptospirosis, while not considering PUUV infection: this would have applied to the patient with hepatitis (sample 16), a probable case of acute hantavirus infection in our study. Atypical presentation of HFRS, as seen in some of the cases listed in Table 2 (samples 21 and 19), has been the subject of several recent case reports $[7,32,33]$. However, unawareness and/or lack of clinicians' knowledge of how to recognise hantavirus disease could also be a reason for underdiagnosis.

Cases may also be underdiagnosed if the patients are outside the hantavirus-endemic area in the Netherlands. Such cases might not be identified due to the low, but clinically important number of infections, resulting in lack of awareness of the clinicians in these areas. If we compare the distribution of the previously undiagnosed cases in our cohort with the earlier serological data, for instance, data published by Groen et al. [14], 7 of 10 cases of hantavirus infection not tested at the time of sampling for hantavirus disease (listed in Table 2) were from outside the known endemic area. Our conclusions regarding underdiagnosis are supported by a recent study showing $1.7 \%$ hantavirus seroprevalence in the Dutch population, which should lead to more symptomatic cases than the 25-30 cases reported annually [15].

In this relatively small cohort with specific clinical indications for leptospirosis diagnostics, we have shown the presence of undiagnosed hantavirus cases. Leptospirosis itself is potentially an often-missed diagnosis in the Netherlands, due to unawareness [19]. It is conceivable that physicians, who do not include leptospirosis in their differential diagnosis, are even less aware of the possibility of hantavirus infections. Vice versa, it cannot be excluded that clinicians who are aware of hantavirus infections might miss potential leptospirosis. This hypothesis could be validated by performing larger-scale serological studies with broader cohorts, comprising patients who are suspected of having leptospirosis or hantavirus infection.

On the basis of the results in this paper, we feel it is important to increase awareness of hantavirus infection in the Netherlands. The increased incidence of hantavirus infections in Europe in recent years makes this even more important. This increase is affected by a multitude of factors. Some, such as changes in landscape architecture (e.g. (de)forestation, fragmentation of land by motorways, railways and agriculture and available burrow space) and increased food availability for the rodent reservoirs, are beneficial for the spread of hantaviruses [12]. The introduction or discovery of new hantavirus strains in Europe has been documented [23] and presents another major concern, necessitating epidemiological monitoring of vectors and patients. We advise that hantavirus and leptospirosis diagnostics should be considered for every patient with an undifferentiated fever in any area with potential rodent-borne infections, including typing of the causative agents if the results are positive. 
By decreasing the unnecessary use of antibiotics [34] and providing clinicians with an accurate prediction of the disease course and a choice of adequate biomarkers of disease severity [3], the identification of hantavirus infections might have a limited, but important, clinical importance. Furthermore, adequately diagnosing and typing hantavirus infections is of major public health importance in order to correctly identify and educate risk groups and to design tailor-made prevention programmes, such as rodent-control programmes and changes to landscape architecture.

\section{Acknowledgements}

The authors would like to acknowledge Sjoerd Kuiling for the help with IFA testing.

This study was partially funded by European Union grant FP7261504 EDENext and is catalogued by the EDENext Steering Committee as EDENext225 (http://www.edenext.eu).

\section{Conflict of interest}

None declared.

\section{Authors' contributions}

Marco Goeijenbier, Rudy Hartskeerl, Jiri Wagenaar, Marga Goris, Byron Martina, Eric van Gorp and Chantal Reusken designed the experiment. Marco Goeijenbier, Marga Goris, Johan Reimerink, Jenny Verner-Carlsson and Chantal Reusken did all the laboratory work and experiments. Ake Lundkvist, Eric van Gorp, Byron Martina, Chantal Reusken, Johan Reimerink, Rudy Hartskeerl, Albert Osterhaus and Marion Koopmans assisted with interpretation of the data. All authors contributed to the writing of the manuscript.

\section{References}

1. Watson DC, Sargianou M, Papa A, Chra P, Starakis I, Panos G. Epidemiology of Hantavirus infections in humans: a comprehensive, global overview. Crit Rev Microbiol. 2014; $40(3): 261-72$.

http://dx.doi.org/10.3109/1040841X.2013.783555

2. Bi Z, Formenty PB, Roth CE. Hantavirus infection: a review and global update. J Infect Dev Ctries. 2008;2(1):3-23. http://dx.doi.org/10.3855/iidc.317

3. Goeijenbier M, Wagenaar J, Goris M, Martina B, Henttonen $\mathrm{H}$, Vaheri A, et al. Rodent-borne hemorrhagic fevers: underrecognized, widely spread and preventable - epidemiology, diagnostics and treatment. Crit Rev Microbiol. 2013;39(1):2642.

http://dx.doi.org/10.3109/1040841X.2012.686481

4. Heyman P, Ceianu CS, Christova I, Tordo N, Beersma M, João Alves M, et al. A five-year perspective on the situation of haemorrhagic fever with renal syndrome and status of the hantavirus reservoirs in Europe, 2005-2010. Euro Surveill. 2011;16(36):pii=19961.

5. Vaheri A, Strandin T, Hepojoki J, Sironen T, Henttonen H, Mäkelä S, et al. Uncovering the mysteries of hantavirus infections. Nat Rev Microbiol. 2013;11(8):539-50. http://dx.doi.org/10.1038/nrmicro3066

6. Gerding MN, Groen J, Jordans JG, Osterhaus AD. Hantavirus nephropathy in The Netherlands: clinical, histopathological and epidemiological findings. Neth J Med. 1995;47(3):106-12. http://dx.doi.org/10.1016/0300-2977(95)00054-Q

7. Gizzi M, Delaere B, Weynand B, Clement J, Maes P, Vergote $\checkmark$, et al. Another case of "European hantavirus pulmonary syndrome" with severe lung, prior to kidney, involvement, and diagnosed by viral inclusions in lung macrophages. Eur J Clin
Microbiol Infect Dis. 2013;32(10):1341-5 http://dx.doi.org/10.1007/s10096-013-1885-x

8. Christova I, Younan R, Taseva E, Gladnishka T, Trifonova I, lvanova V, et al. Hemorrhagic fever with renal syndrome and Crimean-Congo hemorrhagic fever as causes of acute undifferentiated febrile illness in Bulgaria. Vector Borne Zoonotic Dis. 2013;13(3):188-92.

http://dx.doi.org/10.1089/vbz.2011.0938

9. Reusken CB. Hantavirus infections in the Netherlands, a risk profile. Bilthoven: National Institute for Public Health and the Environment (RIVM); 2009 RIVM Letter report 330361001/2009. Available from: http://www.rivm.nl/dsresource?objectid=rivmp :13325\&type=org\&disposition=inline\&ns_nc=1

10. Heyman P, Cochez C, Ducoffre G, Mailles A, Zeller H, Abu Abu Sin M, et al. Haemorrhagic Fever with Renal Syndrome: an analysis of the outbreaks in Belgium, France, Germany, the Netherlands and Luxembourg in 2005. Euro Surveill. 2007;12(5): $\mathrm{pii}=712$.

11. Boone I, Wagner-Wiening C, Reil D, Jacob J, Rosenfeld UM, Ulrich RG, et al. Rise in the number of notified human hantavirus infections since October 2011 in BadenWurttemberg, Germany. Euro Surveill. 2012;17(21):pii=20180.

12. Reusken C, Heyman P. Factors driving hantavirus emergence in Europe. Curr Opin Virol. 2013;3(1):92-9. http://dx.doi.org/10.1016/j.coviro.2013.01.002

13. Groen J, Gerding MN, Jordans JG, Clement JP, Nieuwenhuijs $\mathrm{H}$, Osterhaus AD. Hantavirus infections in The Netherlands: epidemiology and disease. Epidemiol Infect. 1995;114(2):37383. http://dx.doi.org/10.1017/S0950268800058003

14. Gerding MN, Groen J, Jordans JG,Osterhaus AD. Hantavirus nephropathy in The Netherlands: clinical, histopathological and epidemiological findings. Neth J Med. 1995;47(3):106-12. http://dx.doi.org/10.1016/0300-2977(95)00054-Q

15. Van der Klis F, Mollema L, Van Weert Y. RIVM report: Pienter 2 study; a summary of the main findings. Bilthoven: National Institute for Public Health and the Environment (RIVM); 2012. RIVM Letter report. Available on request.

16. Vaheri A, Henttonen H, Voutilainen L, Mustonen J, Sironen T, Vapalahti 0. Hantavirus infections in Europe and their impact on public health. Rev Med Virol. 2013;23(1):35-49. http://dx.doi.org/10.1002/rmv.1722

17. Centraal Bureau voor de Statistiek (CBS). Bevolkingsteller. [Population counter]. The Hague: CBS. [Accessed 22 Feb 2014]. Dutch. Available from: http://www.cbs.nl/nl-NL/menu/themas/ bevolking/cijfers/extra/bevolkingsteller.htm

18. Goeijenbier M, Nur E, Goris M, Wagenaar JF, Grunberg K, Nurmohamed SA, et al. An unusual cause of a usual presentation. Hantavirus infection. Neth J Med. 2011;69(6):285-9.

19. Goris MG, Boer KR, Duarte TA, Kliffen SJ, Hartskeerl RA. Human leptospirosis trends, the Netherlands, 1925-2008. Emerg Infect Dis. $2013 ; 19(3): 371-8$ http://dx.doi.org/10.3201/eid1903.111260

20. Gamage CD, Yasuda SP, Nishio S, Kularatne SA, Weerakoon K, Rajapakse J, et al. Serological evidence of Thailand virus related hantavirus infection among suspected leptospirosis patients in Kandy, Sri Lanka. Jpn J Infect Dis. 2011;64(1):72-5.

21. Nuti M, Amaddeo D, Autorino GL, Crovatto M, Crucil C, Ghionni A, et al. Seroprevalence of antibodies to hantaviruses and leptospires in selected Italian population groups. Eur J Epidemiol. 1992;8(1):98-102.

22. Jameson LJ, Taori SK, Atkinson B, Levick P, Featherstone CA, van der Burgt $G$, et al. Pet rats as a source of hantavirus in England and Wales, 2013. Euro Surveill. 2013;18(9):pii=20415.

23. Jameson LJ, Logue CH, Atkinson B, Baker N, Galbraith SE, Carroll MW, et al. The continued emergence of hantaviruses: isolation of a Seoul virus implicated in human disease, United Kingdom, October 2012. Euro Surveill. 2013;18(1): $\mathrm{pii}=20344$.

24. Macé G, Feyeux C, Mollard N, Chantegret C, Audia S, Rebibou JM, et al. Severe Seoul hantavirus infection in a pregnant woman, France, October 2012. Euro Surveill. 2013;18(17): $\mathrm{pii}=20464$.

25. Goris MG, Leeflang MM, Boer KR, Goeijenbier M, van Gorp EC, Wagenaar JF, et al. Establishment of valid laboratory case definition for human leptospirosis. J Bacteriol Parasitol. 2012;3:132.

26. Tersago K, Verhagen R, Servais A, Heyman P, Ducoffre G, Leirs $H$. Hantavirus disease (nephropathia epidemica) in Belgium: effects of tree seed production and climate. Epidemiol Infect. 2009;137(2):250-6. http://dx.doi.org/10.1017/S0950268808000940

27. Lundkvist A, Hukic M, Hörling J, Gilljam M, Nichol S, Niklasson B. Puumala and Dobrava viruses cause hemorrhagic fever with renal syndrome in Bosnia-Herzegovina: evidence of 
highly cross-neutralizing antibody responses in early patient sera. J Med Virol. 1997;53(1):51-9. http://dx.doi.org/10.1002/ (SICI)1096-9071(199709)53:1<51::AID-JMV9>3.3.C0;2-J http://dx.doi.org/10.1002/

SICI)1096-9071(199709)53:1<51::AID-JMV9>3.0.C0;2-P

28. Sironen T, Klingström J, Vaheri A, Andersson LC, Lundkvist A, Plyusnin A. Pathology of Puumala hantavirus infection in macaques. PLoS One. 2008;3(8):e3035.

http://dx.doi.org/10.1371/journal.pone.0003035

29. Lundkvist A, Fatouros A, Niklasson B. Antigenic variation of European haemorrhagic fever with renal syndrome virus strains characterized using bank vole monoclonal antibodies. Gen Virol. 1991;72 (Pt 9):2097-103.

http://dx.doi.org/10.1099/0022-1317-72-9-2097

30. Jameson LJ, Logue CH, Atkinson B, Baker N, Galbraith SE, Carroll MW, et al. The continued emergence of hantaviruses: isolation of a Seoul virus implicated in human disease, United Kingdom, October 2012. Euro Surveill. 2013;18(1): pii=20344.

31. Tischler ND, Rosemblatt M, Valenzuela PD. Characterization of cross-reactive and serotype-specific epitopes on the nucleocapsid proteins of hantaviruses. Virus Res. 2008;135(1):1-9.

http://dx.doi.org/10.1016/j.virusres.2008.01.013

32. Eckerle I, Jakob E, Hofmann J, Schmidt-Bacher A, Ettinger J,

Schnitzler P. Atypical severe Puumala hantavirus infection and virus sequence analysis of the patient and regional reservoir host. Zoonoses Public Health. 2012;59 Suppl 2:110-5. http://dx.doi.org/10.1111/j.1863-2378.2011.01452.x

33. Kramski M, Achazi K, Klempa B, Krüger DH. Nephropathia epidemica with a 6-week incubation period after occupational exposure to Puumala hantavirus. J Clin Virol. 2009;44(1):99101.

http://dx.doi.org/10.1016/j.jcv.2008.10.005

34. Brorstad A, Oscarsson KB, Ahlm C. Early diagnosis of hantavirus infection by family doctors can reduce inappropriate antibiotic use and hospitalization. Scand J Prim Health Care. 2010;28(3):179-84

http://dx.doi.org/10.3109/02813432.2010.506058 